\title{
RADAR METEOROLÓGICO E SUA IMPORTÂNCIA NA PREVISÃo DE DESASTRES NATURAIS
}

\author{
Douglas Cristino Leal ${ }^{(a)}$ \\ (a)Instituto de Geociências, UNICAMP, douglascristinoleal@gmail.com
}

\section{Eixo: GEOGRAFIA FÍSICA E DESASTRES NATURAIS}

\begin{abstract}
Resumo
Apresenta-se neste artigo o histórico e a importância do uso do radar meteorológico utilizado em diversas áreas, inclusive na Geografia, para a previsão de desastres naturais, principalmente desastres do grupo hidrológico e meteorológico. A soma dos eventos associados a furacões, tornados e vendavais, referente aos desastres naturais ocorridos no mundo, estão vinculados às instabilidades atmosféricas severas. Especificamente, nas Américas a maior parte das ocorrências é caracterizada por tempestades, seguido de inundações, totalizando $71 \%$ dos fenômenos registrados. Esses danos mostram a importância do uso dessa preciosa ferramenta, o radar meteorológico, que juntamente com as geotecnologias, obtenção de imagens de satélite e de cartas sinóticas, torna possível conhecer os sistemas atuantes e a origem do fenômeno ocasionado, além dos possíveis danos dentro de sua área de alcance. Esse artigo também conta com uma análise episódica que elucida uma situação de instabilidade atmosférica severa que, sem o radar meteorológico, seria impossível sua análise.
\end{abstract}

Palavras chave: Radar Meteorológico, Desastres Naturais, Tempestades, Tornados, Geotecnologias

\section{Ocorrência de Desastres Naturais no Mundo}

De acordo com Tobin e Montz (1997), os desastres naturais podem ser conceituados, de forma simplificada, como resultado do impacto de um fenômeno natural extremo ou intenso sobre um sistema social, causando sérios danos e prejuízos que excede a capacidade dos afetados em conviver com o impacto.

Ambos classificaram os desastres naturais quanto à tipologia, tendo como premissa o evento geofísico que desencadeou o desastre natural. Estes eventos fazem parte da geodinâmica externa (meteorológicos e hidrológicos) e interna (geológicos) da Terra.

O maior número de ocorrências de desastres naturais, registrado em todo o globo foi do grupo hidrológico e meteorológico. Utilizando os dados do banco global Emergency Events Database (EM-DAT), no período de 1900 a 2013, foi constatado que os maiores registros foram de inundação, seguido de tempestades, sendo 4.283 (37\%) e 3.665 (32\%) ocorrências, respectivamente (Figura 1). 


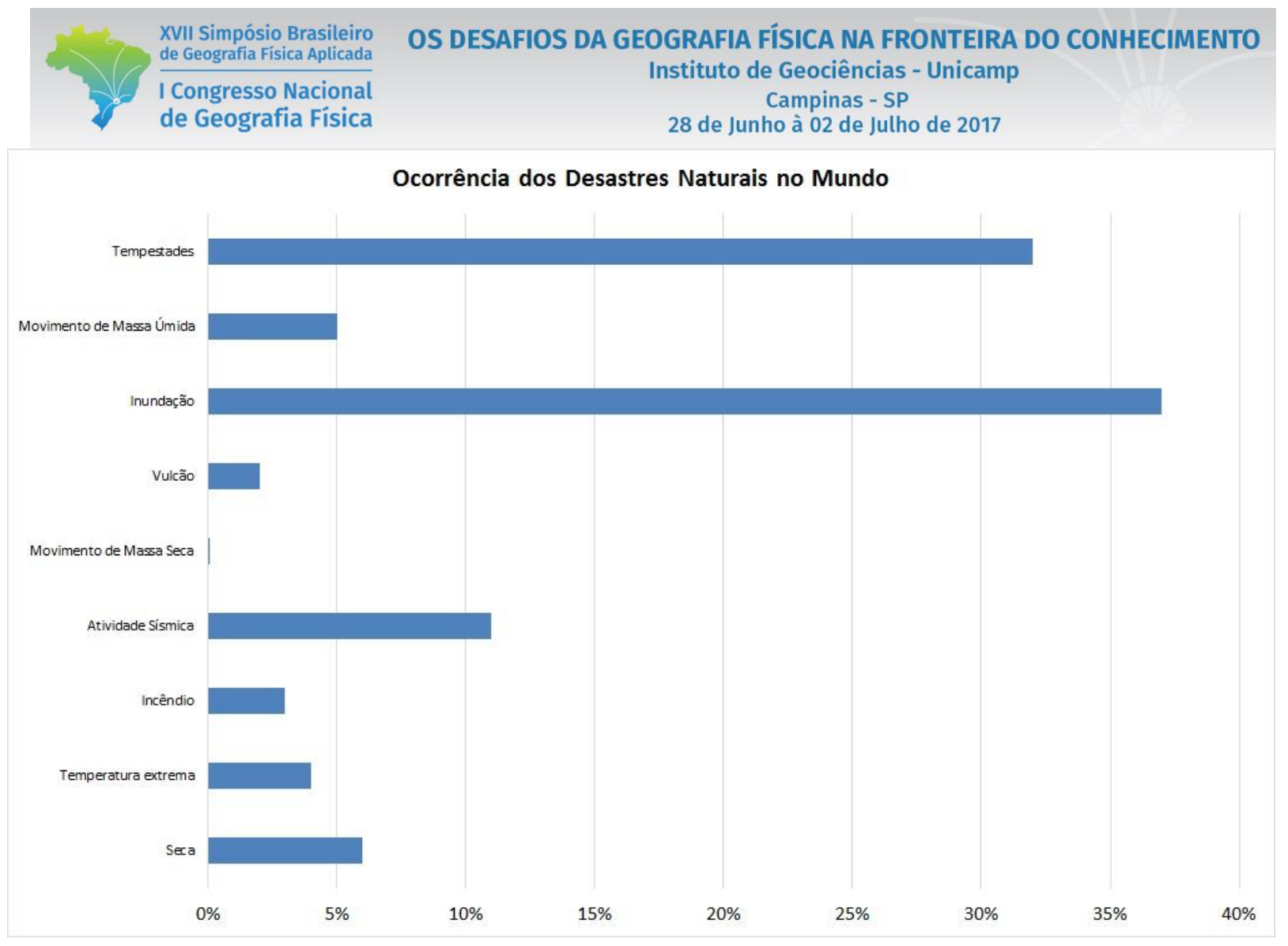

Figura 1 - Frequência das ocorrências de desastres naturais no mundo por subgrupo (1990 a 2013)

Organização: Douglas C. Leal

Fonte: EM-DAT

A soma dos eventos associados a furacões, tornados e vendavais, referente aos desastres naturais ocorridos no mundo, estão vinculados às instabilidades atmosféricas severas. Nas Américas, a maior parte das ocorrências é caracterizada por tempestades (1.190 ocorrências), seguido de inundações (995 ocorrências), totalizando $71 \%$ dos fenômenos registrados (Figura 2).

O estado de São Paulo encontra-se na primeira posição dentre todas as Unidades da Federação a frequente ocorrência de tempestades. Tal panorama se dá por fatores geomorfológicos e climáticos, com destaque para a presença de relevo relativamente plano, existência de massivos corpos d'água e localização transicional do ponto de vista climático. A altitude e a declividade também exercem influência direta na ocorrência do fenômeno, visto que este último elemento proporciona perturbação no movimento do ar junto ao solo, alterando a dinâmica atmosférica em tais locais. Outro fator importante é a concentração populacional desse estado, mais populoso do país, o que faz com que o espraiamento urbano e a ocorrência de ilhas de calor sejam mais comuns nessa área, em detrimento das demais (CANDIDO, 2012). 


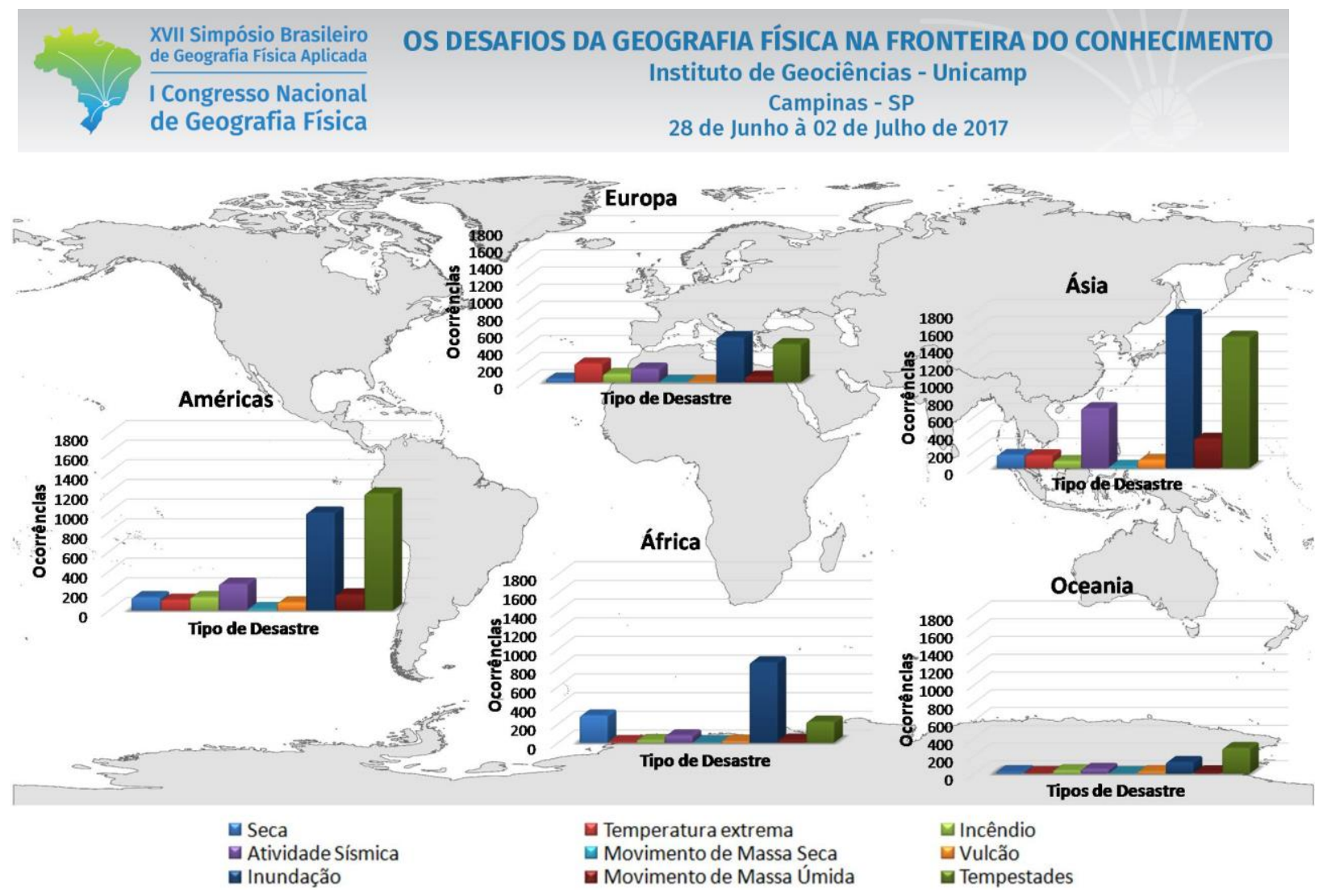

Figura 2 - Desastres naturais ocorridos no mundo por continentes, de 1900 a 2013

Fonte dos dados: EM-DAT, 2014

Organização: Douglas C. Leal

\section{O Radar Meteorológico}

O termo Radar é um acrônimo em inglês para Radio Detection and Ranging, que pode ser traduzido como “detecção e telemetria por ondas de rádio". Substituiu o termo RDF, na década de 1930, e é acrônimo de Radio Direction Finding, do inglês, ou localização de direção por ondas de rádio.

Foi um pouco antes e durante a Segunda Guerra Mundial (SGM) que o radar surgiu como um dispositivo de engenharia prática. Tem suas origens nas pesquisas com rádio de Taylor e Young: dois engenheiros que trabalhavam com rádio para a Marinha Americana no ano de 1922. Perceberam que quando navios passavam entre o transmissor e o receptor, havia reflexões do sinal. Em 1930, Taylor escreveu um relatório para a Marinha sobre eco de sinais de rádio de objetos em movimento, que conduziu ao desenvolvimento do radar (IEEE, 2012).

O primeiro radar surgiu em 1904, pelas mãos de um engenheiro alemão de nome Christian Hulsmeyer que criou um aparelho capaz de detectar a presença de um objeto afastado a alguma distância. O radar teve 


\section{OS DESAFIOS DA GEOGRAFIA FÍSICA NA FRONTEIRA DO CONHECIMENTO \\ Instituto de Geociências - Unicamp \\ Campinas - SP \\ 28 de Junho à 02 de Julho de 2017}

grande desenvolvimento durante a SGM, sendo considerado por alguns autores como "a invenção que mudou o mundo" (BUNDERI, 1997), apesar de ser uma invenção ainda em desenvolvimento (KRAUSE, 2000).

Seu principal desenvolvimento foi durante os anos 1930, quando a Inglaterra se preparava para a SGM, sendo usado para indicar e monitorar navios e aviões de guerra (Figura 3). Sob esse aspecto a chuva obscurecia os alvos e causava grande dificuldade para operadores de radares militares (BATTAN, 1962).

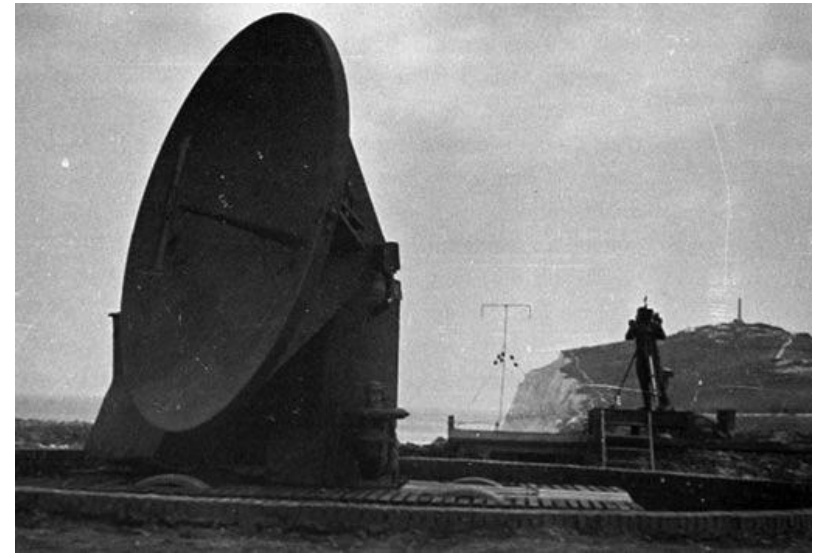

Figura 3 - Radar Wurzburg, utilizado na Segunda Guerra Mundial, de terra, curto alcance (170 km Range), frequência de $560 \mathrm{MHz}$, precisão de $100 \mathrm{~m}$ de alcance e angular de $0,2^{\circ}$

Fonte: http://www.yepteam.com/real-et/radar/e_page6.htm

Em 12 de fevereiro de 1935 Robert Watson-Watt enviou um memorando intitulado "Detecção de aeronaves por meio de métodos de rádio", que Hanbury Brown chama de "a certidão de nascimento de radar". Durante a guerra, o radar desempenhou um papel fundamental no sucesso ou fracasso de muitas missões militares. Por exemplo, durante a década de 1940 Batalha da Grã-Bretanha, um sistema de radar chamado Cadeia Início alertou os britânicos de iminentes ataques aéreos alemães. Este aviso deu tempo aos britânicos de mobilizar eficientemente seus recursos de defesa aérea limitada. É amplamente aceito que o uso do radar virou a maré da batalha e ajudou a Grã-Bretanha conseguir uma vitória decisiva.

Com o final da SGM, muitos dos radares residuais e descartados pelos militares puderam ser adquiridos para uso civil (Figura 4) e os interessados em fazer pesquisas em Meteorologia utilizando o radar, foram os primeiros a adquiri-los (RINEHART, 2004). Desde então, o radar para uso em Meteorologia vem evoluindo de forma constante, primeiramente na parte de seus equipamentos e recentemente em aplicativos de softwares especializados (ibidem). 


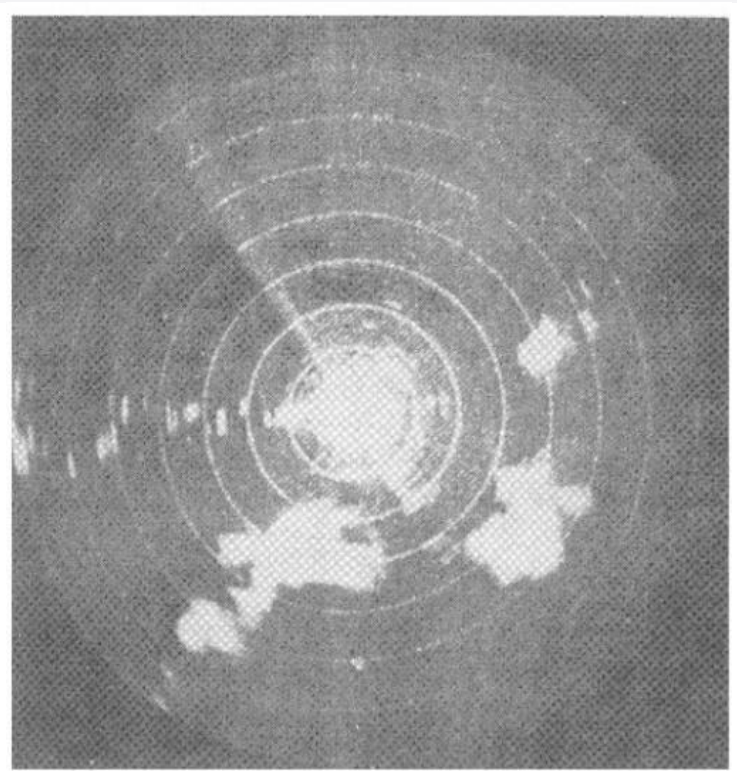

Figura 4 - Imagens das condições de tempestade, em PPI, nas vizinhanças de Cambridge, Massachusetts, 14 de julho de 1942, detectado pelo radar. Marcadores mostram 5 milhas de distância

Fonte: ATLAS, 2015

\section{Radar Meteorológico no Estado de São Paulo}

No estado de São Paulo temos o radar de São Roque, 3 em São Paulo, 1 em Biritiba Mirim, o experimental em Campinas e os radares de Bauru e Presidente Prudente. O de São Roque é da aeronáutica e integrado a Rede de Meteorologia da Aeronáutica (Redemet), Banda-S Doppler. Os 3 radares Banda-X de São Paulo, são controlados pelo Instituto de Astronomia, Geofísica e Ciências Atmosféricas (IAG) da Universidade de São Paulo (USP) através do Laboratório STORM-T, coordenado pelo professor Carlos Augusto Morales Rodriguez, que desenvolve pesquisas com o objetivo de entender os processos físicos relacionados à formação e desenvolvimento de tempestades atmosféricas (STORM-T, 2017)

Também há o Radar Ponte Nova que é operado pela Fundação Centro Tecnológico de Hidráulica e Recursos Hídricos, de propriedade do Departamento de Águas e Energia Elétrica (DAEE), autarquia da Secretaria de Recursos Hídricos, Saneamento e Obras do estado de São Paulo, localizado na cabeceira do rio Tietê, no município de Biritiba Mirim (SAISP, 2017)

Em Campinas tem o projeto SOS CHUVA (INPE, 2017), financiado pela Fundação de Amparo do Pesquisador do Estado de São Paulo (FAPESP), do professor Luís Augusto Machado que, por 24 meses (duas estações chuvosas), tem o objetivo de para capturar eventos intensos de precipitação que forneçam as bases para o estudo dos processos físicos no interior das nuvens visando aprimorar a previsibilidade em 
curto prazo, a detecção de severidade e a estimativa de precipitação com radar e satélite em alta resolução temporal e espacial. De forma inédita esse projeto irá instalar detectores de granizo para criar uma base de dados que forneça informações não somente sobre a ocorrência de granizo, mas também do seu tamanho.

Por fim, os radares de Bauru e Presidente. É inerente maior destaque para esses radares, uma vez que são os únicos radares com dados volumétricos e capacidade Doppler disponível com mais de 15 anos de observações contínuas. Ambos são operados e mantidos pelo Centro de Meteorologia de Bauru (CMB) Faculdade de Ciências, antigo Instituto de Pesquisas Meteorológicas (IPMet) da Universidade Estadual Paulista (UNESP), situado em Bauru. Ambos possuem capacidade Doppler, que permite não só a determinação das intensidades de precipitação, mas também indica a velocidade dos movimentos das partículas de precipitação ao longo das radiais, isto é, se as partículas estão se movendo em direção ao radar ou se estão se afastando do radar. Desta forma, o processamento Doppler (ou processamento coerente) tem desempenhado um importante papel no monitoramento e alerta de tempestades intensas (GOMES, 1993).

Este radar tem feixe $2^{\circ}$ e monitora o espaço no modo de vigilância dentro do raio de $450 \mathrm{~km}$ com resolução temporal de 15 minutos. Para o modo de quantificação de precipitação, o alcance encontra-se em $240 \mathrm{~km}$, com atualização da informação a cada 7,5 minutos e resolução espacial de $1 \mathrm{~km}^{2}$ (ANTONIO, 1998; ANTÔNIO e ANDRADE, 2007). A Figura 5 mostra a rede de radares Doppler do CMB (BRU = Bauru; PPR = Presidente Prudente), com seus respectivos anéis de $240 \mathrm{~km}$ e $450 \mathrm{~km}$, alcances quantitativos e modo vigilância.

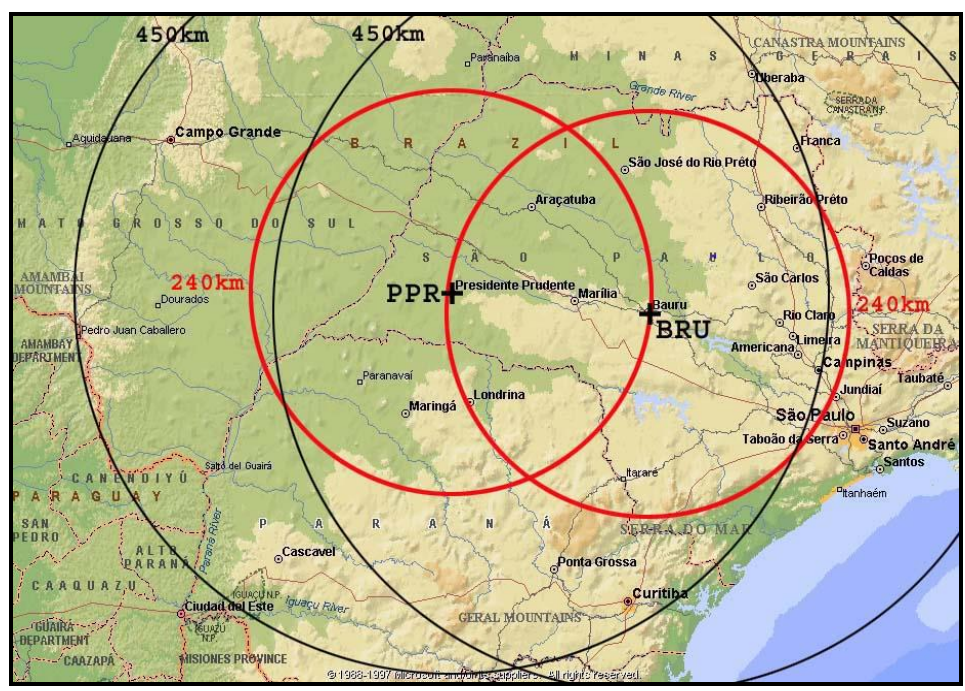

Figura 5 - Rede de radares Doppler do CMB (BRU = Bauru; PPR = Presidente Prudente)

Fonte: Held et al., 2014 


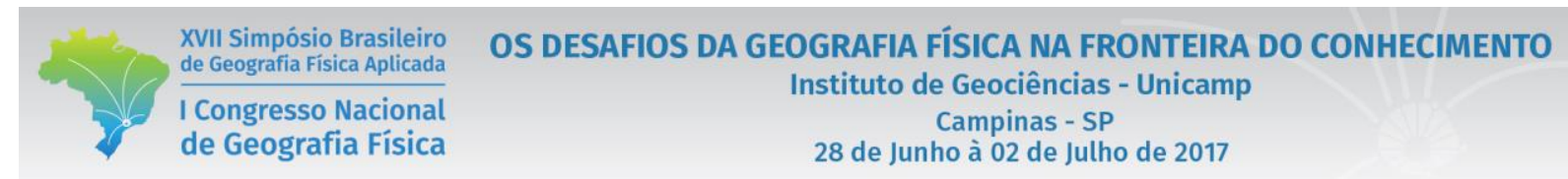

A história do IPMet, atual CMB, teve início em 1969, quando a então Fundação Educacional de Bauru, instituição de ensino superior e futura mantenedora da Universidade de Bauru, implantou o seu Instituto de Pesquisas, com o objetivo de subsidiar as diversas áreas de ensino. A área escolhida pela instituição foi a meteorologia, ciência multidisciplinar que permite a interação com diversas áreas do ensino tecnológico e mesmo com as ciências humanas. Esse instituto contava a princípio, com uma estação receptora de imagens de satélite meteorológico (HELD et al., 2008). O IPMet começou a se destacar com os trabalhos de pesquisa meteorológica e em 1972 houve convênio com o Banco Nacional de Desenvolvimento Econômico (BNDE), para a aquisição de equipamentos a serem utilizados em pesquisas. Em 1974 foi instalado o primeiro radar meteorológico banda-C do IPMet em Bauru, o que garantiu o pioneirismo no país em relação à utilização desse tipo de equipamento (Figura 6).
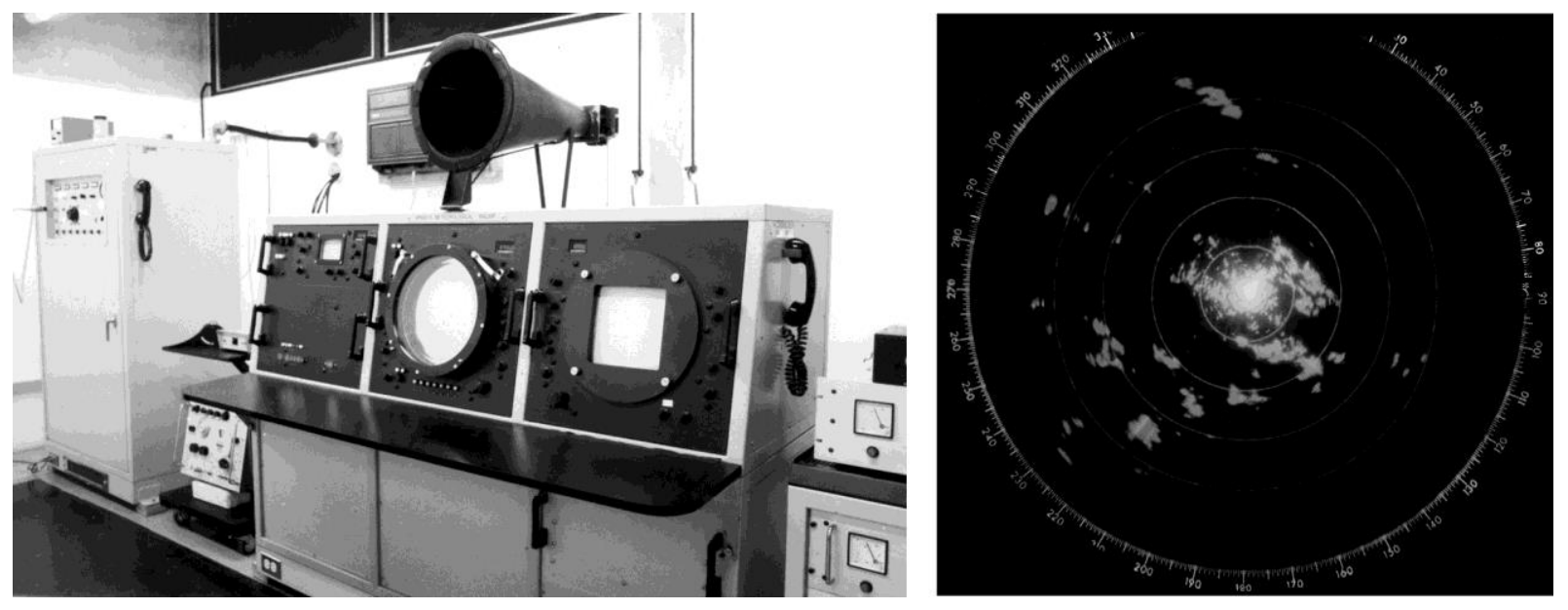

Figura 6 - À esquerda, Radar banda-C com câmera (1974-1992) e à direita, precipitação na tela do radar banda-C: PPI com elevação de $0^{\circ}$ mostrando áreas de chuva no dia 24 de dezembro de 1981 as 15:37 horas local.

Fonte: Acervo histórico do CMB

Em 1992, com recursos obtidos junto à Financiadora de Estudos e Projetos (FINEP), o antigo radar banda$\mathrm{C}$ foi substituído por um equipamento mais atual, modelo banda-S e com capacidade Doppler. Em função de programa de pesquisa desenvolvido junto à Secretaria de Ciência, Tecnologia e Desenvolvimento Econômico do Estado de São Paulo (SCTDE), outro radar banda-S Doppler foi adquirido e instalado na cidade de Presidente Prudente e sendo operado remotamente a partir de Bauru.

Com o avanço da tecnologia e, consequentemente, dos produtos gerados pelo radar Doppler do CMB, os alertas de tempestades, identificação e classificação como severas ou não-severas, estão em grande avanço, minimizando riscos potenciais de danos na área de alcance quantitativo do radar. Os desastres 
naturais estão presentes e não há como evita-los, porém, minimizar os danos à sociedade são possíveis, principalmente quando utilizado o radar meteorológico na previsão em tempo real.

\section{Utilização do Radar para Análises de Instabilidades Atmosféricas Severas}

Como exemplo, de situações de instabilidades atmosféricas severas, temos o episódio de um tornado (F3, Escala Fujita) em Taquarituba-SP (Figura 7), no dia 22 de setembro de 2013, por volta das 14:30 Horário Local (HL), 17:30 Universal Time (UT), com duração de 5 minutos, deixando 2 mortos e cerca de 63 feridos (FOLHA, 2013; Defesa Civil, 2013).

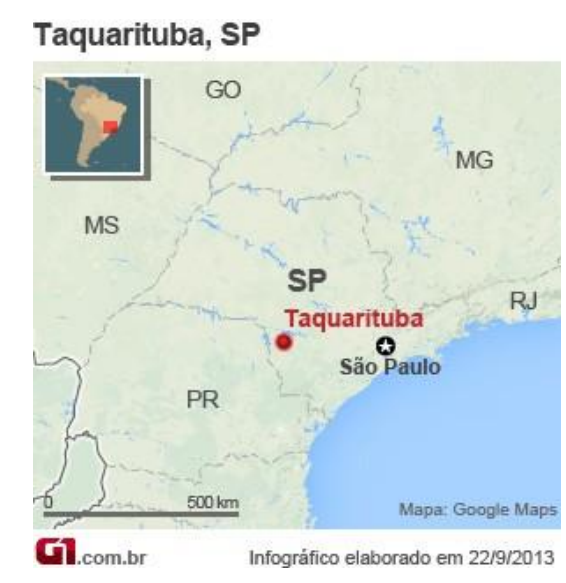

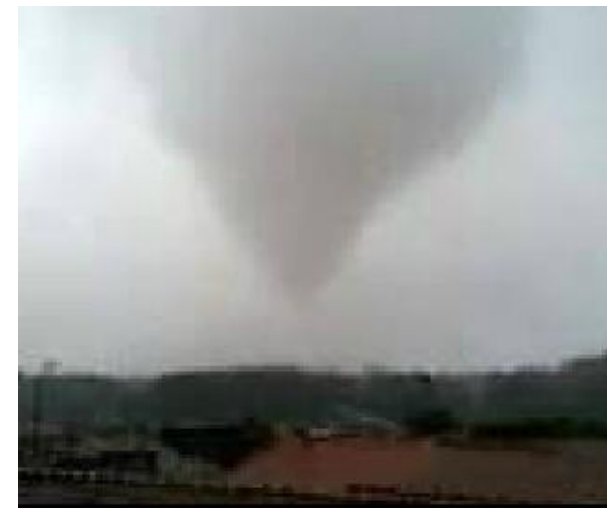

Foto: Reprodução de vídeo

Figura 7 - À esquerda, localização do município de Taquarituba-SP. À direita, imagem do tornado ocorrido no dia 22 de setembro de 2013

$$
\text { Fonte: Globo G1 }
$$

De acordo com o Jornal BOL Notícias (2013), os maiores danos registrados foram no parque industrial do município de Taquarituba no qual estavam instadas 37 empresas. A maioria delas era ligada à agroindústria. Ao todo 20 pessoas ficaram desabrigadas e 150 imóveis foram afetados (Figura 8). 


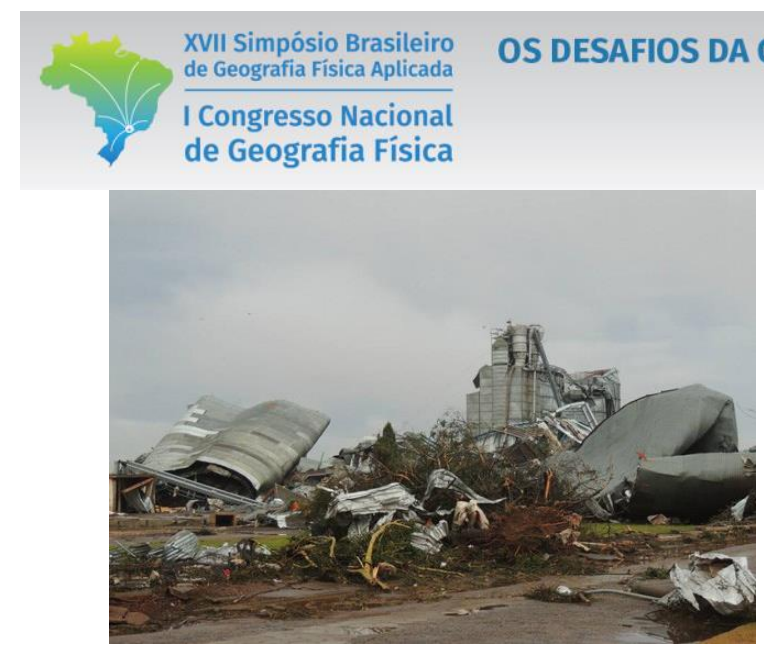

Foto: Ricardo Ossandon/Globo G1
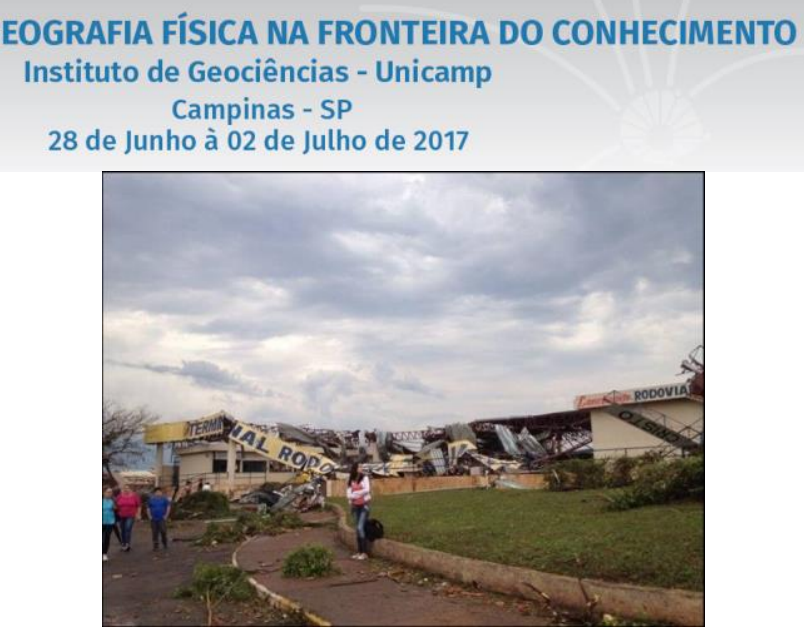

Foto: Mariana Vidal/Você Manda

Figura 8 - À esquerda, escombros da Igreja do Evangelho Quadrangular e, à direita, terminal rodoviário destruído Fonte: Globo G1

A situação sinótica baroclínica (Figura 9) foi muito favorável, devido à aproximação de uma frente fria intensa através do Paraná e atingindo a parte sudeste do estado de São Paulo, criando condições extremamente instáveis, com convecção profunda e "overshooting" de torres até $20 \mathrm{~km}$ (HELD et al. 2014a).
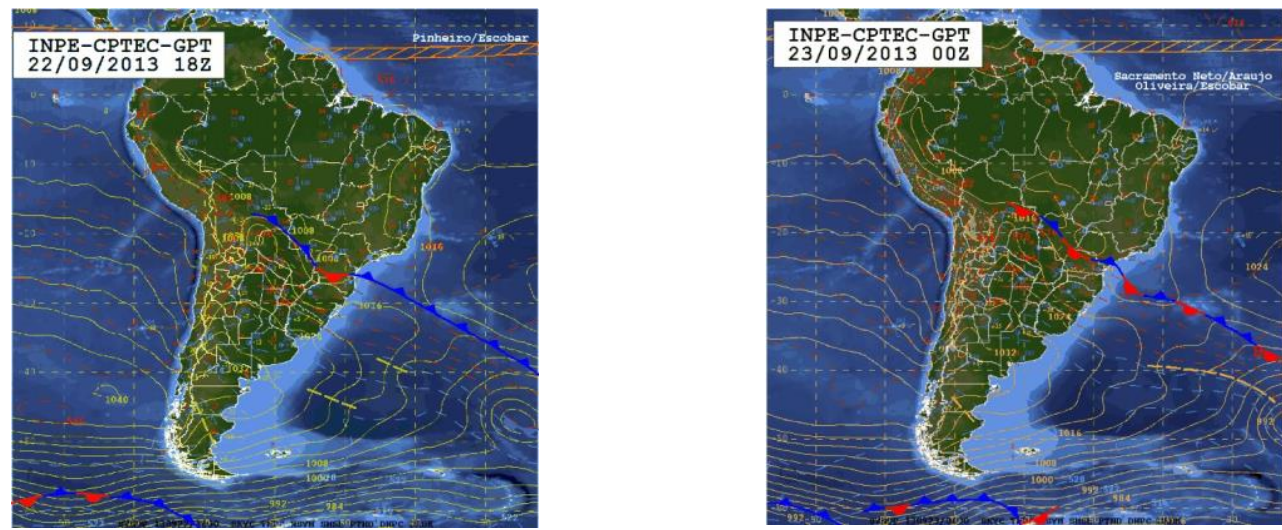

Figura 9 - Avanço da frente fria no estado de São Paulo. Carta Sinótica das 18:00 UT do dia 22 de setembro de 2013 e da 00:00 UT do dia 23 de setembro de 2013

\section{Fonte: CPTEC}

Foi evidenciado que o complexo da tempestade atravessou o rio Paranapanema, e observou-se uma intensificação drástica das células, um pouco antes de atingir a cidade de Taquarituba, onde a célula, em particular, exibiu um cisalhamento radial extremamente forte, pouco acima da base da nuvem (ca de -20 a $+35 \mathrm{~m} / \mathrm{s}$ ), o que levou à formação de um mesociclone profundo até $9 \mathrm{~km}$, a partir do qual o tornado foi 
XVII Simpósio Brasileiro

de Geografia Fisica Aplicada

I Congresso Nacional

de Geografia Física
OS DESAFIOS DA GEOGRAFIA FÍSICA NA FRONTEIRA DO CONHECIMENTO

Instituto de Geociências - Unicamp

Campinas - SP

28 de Junho à 02 de Julho de 2017

gerado, tocando o solo (assinatura do tornado - Bounded Weak Echo Region - BWER), em torno de 14:30

HL (Figura 10), do dia 22 de setembro de 2014 (HELD et al. 2014b).
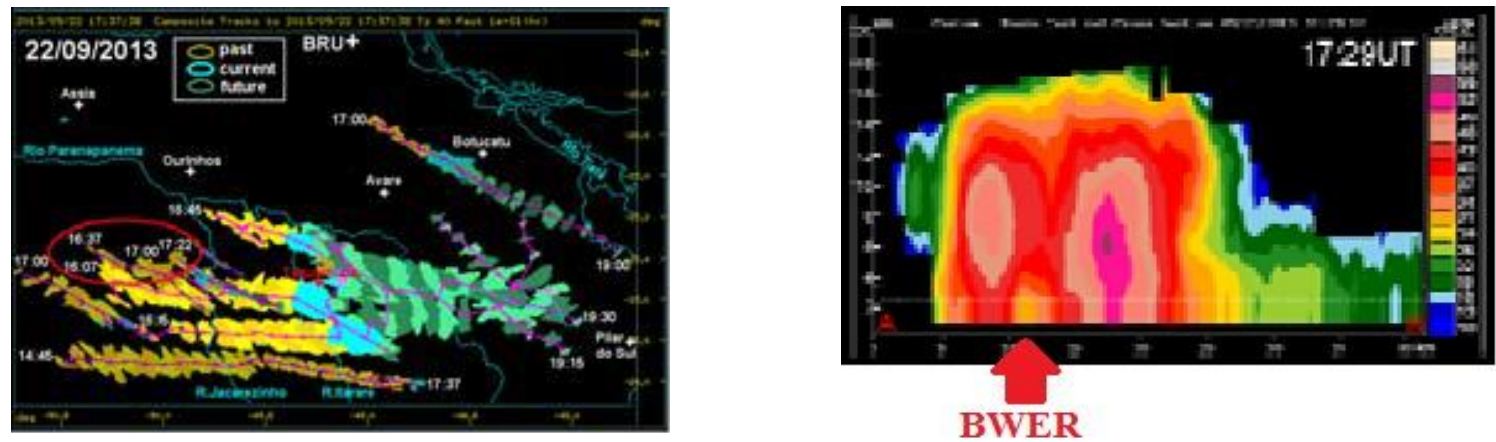

Figura 10 - À esquerda, trajeto dos complexos culminando com o tornado em Taquarituba. Horário de referência é 17:37 UT (14:37 HL, próximo a ocorrência do tornado). À direita, Corte vertical ao longo da linha base A-B, com BWER

Fonte: HELD et al. 2014b

Evidências baseadas em imagens de radar e dos dados coletados pelo mesmo mostra realmente que consistiu em um episódio tornádico. Sem essa ferramenta de grande importância para registro e análise de dados e imagens, seria impossível chegar a tais conclusões e, consequentemente, mitigações dos desastres naturais. A natureza não pode ser controlada, porém, os riscos de danos à sociedade podem ser minimizados caso sejam emitidos alertas com antecedência.

\section{Considerações Finais}

Neste artigo foi abordado o histórico e a importância do uso do radar meteorológico utilizado em diversas áreas, inclusive na Geografia, para a previsão de desastres naturais. É de grande valia a utilização de ferramentas que possam auxiliar na coleta, armazenamento, gerenciamento, processamento e interpretação de dados meteorológicos. A soma dos eventos associados a furacões, tornados e vendavais, referente aos desastres naturais ocorridos no mundo, estão vinculados às instabilidades atmosféricas severas e o radar meteorológico é uma ferramenta primordial para análise das mesmas.

Em todo o globo constatou-se que o maior número de ocorrências de desastres naturais foi do grupo hidrológico e meteorológico. Dados do banco EM-DAT mostram que os maiores registros foram de inundação, seguido de tempestades, sendo 4.283 (37\%) e 3.665 (32\%) ocorrências, respectivamente.

Para elucidar a importância do radar meteorológico no alerta de tempestades, identificação e classificação como severas ou não-severas, houve uma análise episódica. Sem esta ferramenta preciosa, não seria 
possível comprovar a ocorrência do tornado (F3, Escala Fujita) em Taquarituba-SP, no dia 22 de setembro de 2013, por volta das 14:30, horário local, com duração de 5 minutos, deixando 2 mortos e cerca de 63 feridos.

Os desastres naturais estão presentes e não há como evita-los. Minimizar os danos à sociedade é possível, principalmente quando utilizado o radar meteorológico na previsão em tempo real. Acrescentado a utilização integrada de diversas ferramentas como as geotecnologias, obtenção de imagens de satélite e de cartas sinóticas é possível saber os sistemas atuantes e a origem do fenômeno ocasionado. Com a utilização dessas ferramentas, profissionais capacitados e trabalho em conjunto com órgãos públicos responsáveis, a contribuição para a mitigação de danos originados por eventos atmosféricos é significativa.

\section{Bibliografia}

ANTONIO, M. de A. Técnica de ajuste em tempo real de medida de chuva com radar. Tese (Doutorado). Faculdade de Ciências Agronômicas, Universidade Estadual Paulista "Julio de Mesquita Filho", Botucatu, SP, 1998.

ANTONIO, M. de A.; ANDRADE, J.P.M. Inundações em São Carlos, SP: avaliação de chuvas com radar. In: Simpósio Brasileiro de Sensoriamento Remoto, Florianópolis, SC. v. 13, p. 3255-3262, 2007.

ATLAS, D. Radar in Meteorology. Battan Memorial and 40th Anniversary Radar Meteorology Conference. Edited by David Atlas, 2015. American Meteorological Society, Boston, 1990.

BATTAN, L. J. Radar observes the weather Garden City: Doubleday and Co. The Science Study Series. 33, 1962.

BOL. Uma semana após tornado, Taquarituba (SP) calcula prejuízo em R\$ 100 milhões. Disponível em: $<$ https://noticias.bol.uol.com.br/ultimas-noticias/brasil/2013/09/30/uma-semana-apos-tornado-taquarituba-sp-calculaprejuizo-em-r-100-milhoes.htm>. Acesso em 14 de março de 2017.

BUNDERI, R. The Invention That Changed the World: How a Small Group of Radar Pioneers Won the Second World War and Launched a Technological Revolution. 1230 Avenue of the Americas, New York, New York: Touchstone Books, 1997.

CANDIDO, D.H. Tornados e Trombas d'água no Brasil: desenvolvimento de um modelo e proposta de escala de avaliação de danos. 2012. 230 f. Tese (Doutorado em Geociências) - Universidade Estadual de Campinas. 2012.

EM-DAT - Emergency Events Database. Disponível em: 〈http://www.emdat.be/>. Acesso em: 14 de março de 2017.

FOLHA, São Paulo de. Tornado deixa centro de Taquarituba destruído; prefeito decreta calamidade. Disponível em: <http://www1.folha.uol.com.br/cotidiano/2013/09/1346124-tornado-deixa-centro-de-taquaritubadestruido-prefeito-decreta-calamidade.shtml>. Acesso em: 14 de março de 2017.

GOMES, A. M. Tópicos em Meteorologia com Radar. Nota Técnica IPMet, 1993.

HELD G, GOMES AM e CALHEIROS RV. O Instituto de Pesquisas Meteorológicas (IPMet): Serviços para a Sociedade no Estado de São Paulo. Boletim da SBMET, 32, n.1, 27-33, 2008. Disponível em: $<$ http://www.sbmet.org.br/portal2011/publisher/uploads/publicacoes/3 2008 Volume 32 No 1.pdf $>$. Acesso em: 13 de março de 2017. 


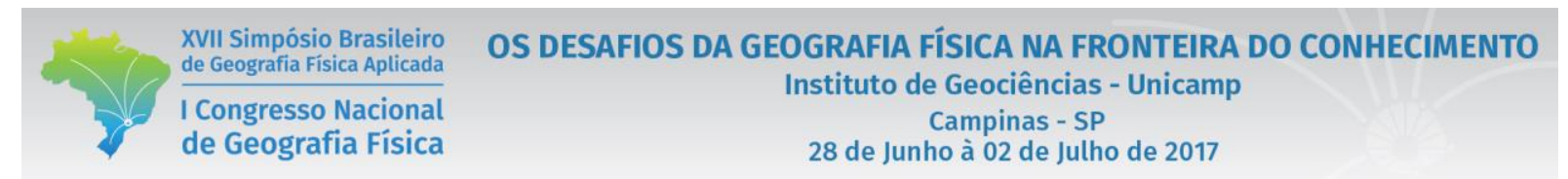

HELD G, GOMES JL e GOMES AM. Radar observations of a tornado-spawning storm complex in Southeast Brazil and Meso-Eta forecasts of this extreme event. Geophysical Research Abstracts, Volume 16, EGU General Assembly 2014, Vienna, Austria, 27 April - 02 May 2014. Disponível em: <http://meetingorganizer.copernicus.org/EGU2014/EGU2014-11437.pdf>. Acesso em: 10 de março de 2017.

HELD G, GOMES JL, GOMES AM e NACCARATO KP. Observações de radar, descargas elétricas e previsões do modelo Meso-Eta para um complexo de tempestade gerando um tornado no Sudeste do Brasil. Proceedings, XVIII Congresso Brasileiro de Meteorologia, Recife, PE, 03-06 de novembro de 2014, SBMET, 2pp. Disponível em: <http://registro-cbmet2014.inteligenciaemeventos.com.br/anais >. Acesso em 12 de março de 2017.

INPE. Projeto SOS CHUVA. Disponível em 〈http://soschuva.cptec.inpe.br/soschuva/projeto.html $>$. Acesso em 14 de março de 2017.

KRAUSE, U. M. M. The Invention That Changed the World: How a Small Group of Radar Pioneers Won the Second World War and Launched a Technological Revolution. Original: abril de 2000. Disponível em: <http://www.airpower.maxwell.af.mil/airchronicles/bookrev/buderi.html >. Acesso em: 14 de março de 2017.

RMC, Portal da. Cepagri da Unicamp em Campinas recebe novo Radar Meteorológico que conseguirá prever alterações climáticas nas cidades da região de Campinas. Disponível em <http://www.portaldarmc.com.br/noticias-da-regiao/2016/08/cepagri-da-unicamp-em-campinas-recebe-novo-radarmeteorologico-que-conseguira-prever-alteracoes-climaticas-nas-cidades-da-regiao-de-campinas/>. Acesso em 13 de março de 2017.

REDEMET. Produtos do Radar. Disponível em: <http://www.redemet.aer.mil.br/>. Acesso em 14 de março de 2017.

RINEHART, R. E. Radar for Meteorologists. Nevada, MO, USA: Rinehart Publications, 2004.

TOBIN, G. A \& MONTZ, B. E. Natural hazards: explanation and integration. New York: The Guilford Press, 1997.

SAISP. Sistema de Alerta a Inundações de São Paulo. Disponível em: <http://www.saisp.br/site/radar1.htm>. Acesso em: 10 de março de 2017.

STORM-T. Sensoriamento Remoto Meteorológico de Tempestades. Disponível em: < http://stormt.iag.usp.br/home/>. Acesso em 11 de março de 2017. 